\title{
Attention and Emotional States during Horticultural Activities of Adults in 20s Using Electroencephalography: A Pilot Study
}

\author{
A-Young Lee ${ }^{1,2,+} \mathbb{D}$, Seon-Ok Kim ${ }^{1,3,+} \mathbb{D}$ and Sin-Ae Park $1,3,4, * \mathbb{D}$ \\ 1 Plant, Environment and Health Lab, Konkuk University, Seoul 05029, Korea; \\ danapre0302@gmail.com (A.-Y.L.); kso0804@naver.com (S.-O.K.) \\ 2 Department of Horticulture and Landscape Architecture, National Taiwan University, Taipei 106032, Taiwan \\ 3 Department of Bio and Healing Convergence, Graduate School, Konkuk University, Seoul 05029, Korea \\ 4 Department of Systems Biotechnology, Konkuk Institute of Technology, Konkuk University, \\ Seoul 05029, Korea \\ * Correspondence: sapark42@konkuk.ac.kr \\ + These authors contributed equally to this work.
}

Citation: Lee, A.-Y.; Kim, S.-O.; Park, S.-A. Attention and Emotional States during Horticultural Activities of Adults in 20s Using Electroencephalography: A Pilot Study. Sustainability 2021, 13, 12968. https://doi.org/10.3390/ su132312968

Academic Editor: Åsa Gren

Received: 12 October 2021

Accepted: 19 November 2021

Published: 24 November 2021

Publisher's Note: MDPI stays neutral with regard to jurisdictional claims in published maps and institutional affiliations.

Copyright: (C) 2021 by the authors Licensee MDPI, Basel, Switzerland. This article is an open access article distributed under the terms and conditions of the Creative Commons Attribution (CC BY) license (https:// creativecommons.org/licenses/by/ $4.0 /)$

\begin{abstract}
Since indoor, sedentary lifestyles became prevalent in society, humans have lost a sustainable connection to nature. An intervention utilizing outdoor horticultural activities could address such a challenge, but their beneficial effects on the brain and emotions have not been characterized in a quantitative approach. We aimed to investigate brain activity and emotional changes in adults in their 20s during horticultural activity to confirm feasibility of horticultural activity to improve cognitive and emotional states. Sixty university students participated in 11 outdoor horticultural activities at 2-min intervals. We measured brain waves of participants' prefrontal cortex using a wireless electroencephalography device while performing horticultural activities. Between activities, we evaluated emotional states of participants using questionnaires. Results showed that each horticultural activity showed promotion of brain activity and emotional changes at varying degrees. The participants during physically intensive horticultural activities-digging, raking, and pruning-showed the highest attention level. For emotional states, the participants showed the highest fatigue, tension, and vigor during digging and raking. Plant-based activities-harvesting and transplanting plants-made participants feel natural and relaxed the most. Therefore, this pilot study confirmed the possibility of horticultural activity as a short-term physical intervention to improve attention levels and emotional stability in adults.
\end{abstract}

Keywords: gardening; horticultural therapy; nature exposure; physical activity; wearable device

\section{Introduction}

People in modern life spend most of their time in indoor environments supported by the statistics showing 95\% of individual's activities take place indoors [1]. The sedentary lifestyle and the lack of physical activity in modern society due to urbanization and hightech development is a universal trend worldwide [2,3]. In addition, due to the recent global COVID-19 pandemic, home isolation, and social distancing, the time spent indoors is increasing and the sedentary lifestyle is spreading more worldwide [4].

By definition, sedentary behavior features being in an awake state, doing activities in sitting, reclining, or lying positions. The average energy expenditure during sedentary behavior is $<1.5$ of the metabolic equivalent of task (MET) [5]. Adults in the US and Canada spent about $9-11 \mathrm{~h}$ (55-70\% of waking hours) in sedentary life [6,7], and those in Korea, about $8 \mathrm{~h}$ [8], challenging individuals to take part in necessary physical activity. More than $28 \%$ of the world's adults aged 18 and over do not meet the recommended amount of physical activity [9].

This sedentary lifestyle and the lack of physical activity leads to negative health outcomes, including not only deterioration of physical health, the onset of chronic diseases 
(e.g., type 2 diabetes, metabolic syndrome, cardiovascular disease), but also deterioration of emotional and cognitive health [2,3]. In particular, a number of stress factors in daily life caused by sedentary behavior could worsen depression, drinking and smoking habits, social isolation, and sleep disturbance, which can eventually lead to attention deficit and cognitive impairment $[10,11]$.

Meanwhile, regular connection of humans with nature has a positive effect on overall wellbeing [12] as nature could serve as a vital health resource [13]. Three key theories (Biophilia hypothesis, Attention restoration theory, and Psycho-evolutionary stress reduction theory) exist and emphasize the restorative effects of the natural environment on human health, accounting for the human relationship with nature [14-16]. Previous studies reported several merits of being connected to nature. Examples are improvements in physical (reductions in blood pressure, body weight, or cholesterol, and increases in physical function, balance, etc.), emotional (relief of stress, changes to positive mood, inhibition of impulse, and increases in self-esteem), and cognitive (increases in attention and memory) functions of humans $[17,18]$. Furthermore, sustainability is the process of conserving and protecting natural resources and ecosystems to support human health and wellbeing, now and in the future $[19,20]$. It was emphasized that reconnecting humans with nature could bring about the recovery of cognitive functions, leading to enhancement of sustainability [19].

Horticultural activities (HA) allow for dynamic interactions with natural objects. While HA enable active participation and involvement with nature [21], they also serve as aerobic physical activities that require low-to-high energy expenditure with a wide range of muscles from the entire body [22,23]. For this reason, when employed as physical activities, HA are reported to provide physical, emotional, and cognitive health benefits [18,24]. Thus, as "green exercise", HA can connect humans with nature, helping to improve the health or wellbeing of individuals while playing a role as preventative measures to the sedentary lifestyle or the lack of exercise. Park et al. [24] investigated the effects of HA on cognitive health when implemented as physical activities. They found increased activities in serotonin and tryptophan biosynthesis metabolisms, meaning feelings of happiness of the participants in a HA program, which led to significant increases in brain-derived neurotrophic factor (BDNF) levels, meaning improved memory function [24]. Studies also showed that the visual stimulation by green plants provides emotional stability and relaxation, such as decreased blood flow in the prefrontal lobe and stabilized the autonomic nervous system in the study participants [25]. Furthermore, various clinical studies showed that improvement in attention and emotional health could be achieved through HA programs using questionnaire-based approaches [26,27]. Nonetheless, these studies could not explain what the basis of such beneficial effects from HAs was. Until recent years, HA professionals and related practitioners alike have assumed that HAs can be utilized to improve attention and emotional health, but it has not been firmly rooted on a scientific basis, the gap in the knowledge. Thus, in order to close the gap, we collected quantitative and objective data on changes in attention and emotional states during HAs.

Electroencephalography (EEG) is a non-invasive wearable-device for electrical activity, monitoring the macroscopic activity at the surface layer of the brain [28]. Collection and analysis techniques of neurological and physiological data by EEG are widely used not only in clinical medicine, but also neuroscience, cognitive science, cognitive psychology, and psychophysiological research [29]. EEG bands of alpha, beta, gamma, and theta waves are used in analyzing various psychophysiological states of the participants. With recent advances in analytic techniques, secondary parameter estimates of the EEG waves, e.g., power spectrum analysis, have allowed for an in-depth examination of the attention states of the participants [29]. In addition, Kim et al.'s studies reported that HA can create greater positive changes, like greater activation of brain activity, attention, recovery in emotions, etc., compared with other recreational activities using EEG [30,31]. However, characterization of each HA on brain activity or emotional health of individuals has not been conducted yet. Therefore, the research question we posed was: what are the 
characteristics and changes in attention and emotional states while participating in various HAs? To assess feasibility of this, we designed the present pilot study to identify attention and emotional state during various HA tasks by examining the electroencephalography (EEG) of the participants.

\section{Materials and Methods}

\subsection{Participants}

We recruited a total of 60 university students in their 20s (male 30, female 30; average age: $24.97 \pm 2.62$ years) (Table 1). For recruitment, we posted a flier about the research on the university homepage online. Only individuals who are right-hand dominant were selected because hand gestures between the dominant and nondominant hands differ during cortical activity [32]. The selected individuals were requested to provide a consent form before volunteering for the study. The participants were asked to fast for $2 \mathrm{~h}$ before the experiment because caffeine or any other kind of oral stimulants can affect brain activity [33]. Once they came to an experimental garden at Konkuk University, they were also asked to complete a demographic questionnaire including age, gender, and body composition. We profiled their body composition — height (Ok7979; Samhwa, Seoul, Korea), body weight, and body mass index (BMI) (ioi 353; Jawon Medical, Gyeongsan, Korea). Upon completion of the study, the participants were provided $\$ 20$ as a reward. The Institutional Review Board of Konkuk University approved this study (7001355-201809-HR-268).

Table 1. Demographic information of participants who participated in this study.

\begin{tabular}{|c|c|c|c|c|}
\hline \multirow{2}{*}{ Variable } & Male $(n=30)$ & Female $(n=30)$ & Total $(n=60)$ & \multirow{2}{*}{ Significance $^{a}$} \\
\hline & \multicolumn{3}{|c|}{$\mathbf{M} \pm \mathbf{S D}$} & \\
\hline Age (years) & $25.53 \pm 2.49$ & $24.40 \pm 2.67$ & $24.97 \pm 2.62$ & NS \\
\hline Height $(\mathrm{cm})^{b}$ & $175.70 \pm 6.01$ & $160.39 \pm 5.69$ & $168.17 \pm 9.66$ & $0.000^{* * *}$ \\
\hline Body weight $(\mathrm{kg})^{\mathrm{c}}$ & $75.25 \pm 12.99$ & $54.58 \pm 8.48$ & $65.09 \pm 15.09$ & $0.000^{* * *}$ \\
\hline Body mass index $\left(\mathrm{kg} \cdot \mathrm{m}^{-2}\right)^{\mathrm{c}}$ & $24.21 \pm 3.52$ & $21.64 \pm 2.22$ & $22.95 \pm 3.20$ & $0.001^{* *}$ \\
\hline
\end{tabular}

a Statistical significance of differences by gender was determined using the independent $t$-test with the following significance codes: $* *, * * *$ significant at $p=0.01,<0.001$ level, respectively, NS, not significant. ${ }^{\mathrm{b}}$ Height was measured using an anthropometer (Ok7979; Samhwa, Seoul, Korea). ${ }^{c}$ Body weight and body mass index was measured using a body fat analyzer (ioi 353; Jawon Medical, Gyeongsan, Korea); Body mass index was calculated using the formula [weight $(\mathrm{kg})] /\left[\right.$ height $\left.(\mathrm{m})^{2}\right]$.

\subsection{Experimental Condition and Procedure}

We arranged $1.0 \mathrm{~m} \times 1.8 \mathrm{~m}$ garden space at an experimental garden on the Konkuk University campus. The average temperature, relative humidity, and light intensity during the experiment were $16.95 \pm 4.54{ }^{\circ} \mathrm{C}, 40.64 \pm 11.89 \%$, and $5962.62 \pm 4367.62 \mathrm{~lx}$, respectively.

The duration of the experiment was $90 \mathrm{~min}$ on average per participant. Before performing HA tasks, the participants were given a 1-min rest on a chair for baseline measurement. After resting, the participants were randomly assigned to a HA task for $2 \mathrm{~min}$, and then asked to fill out a questionnaire to record the emotional state of the participants. This measurement cycle consists of a 1-min rest, a 2-min task, and a survey was repeated until the participants completed all of the 11 HA tasks we designed (Table 2, Figure 1). The experimental protocol of this study was established through a preliminary test, referring to previous studies that investigated the characteristics of HA through EEG measurement $[30,31]$. For the protocol of this study, to investigate each HA's characteristics, the optimal task time and the rest time were set to obtain reliable data without being influenced by each other between each activity. The immediate response of the brain waves and the autonomic nervous system to specific stimuli allows these short response time settings [30,31]. The HA tasks assigned to the participants were conducted in the same way as described in a standard operating procedure developed in previous studies [23,34]. 
Table 2. Description of horticultural activities performed by participants in this study.

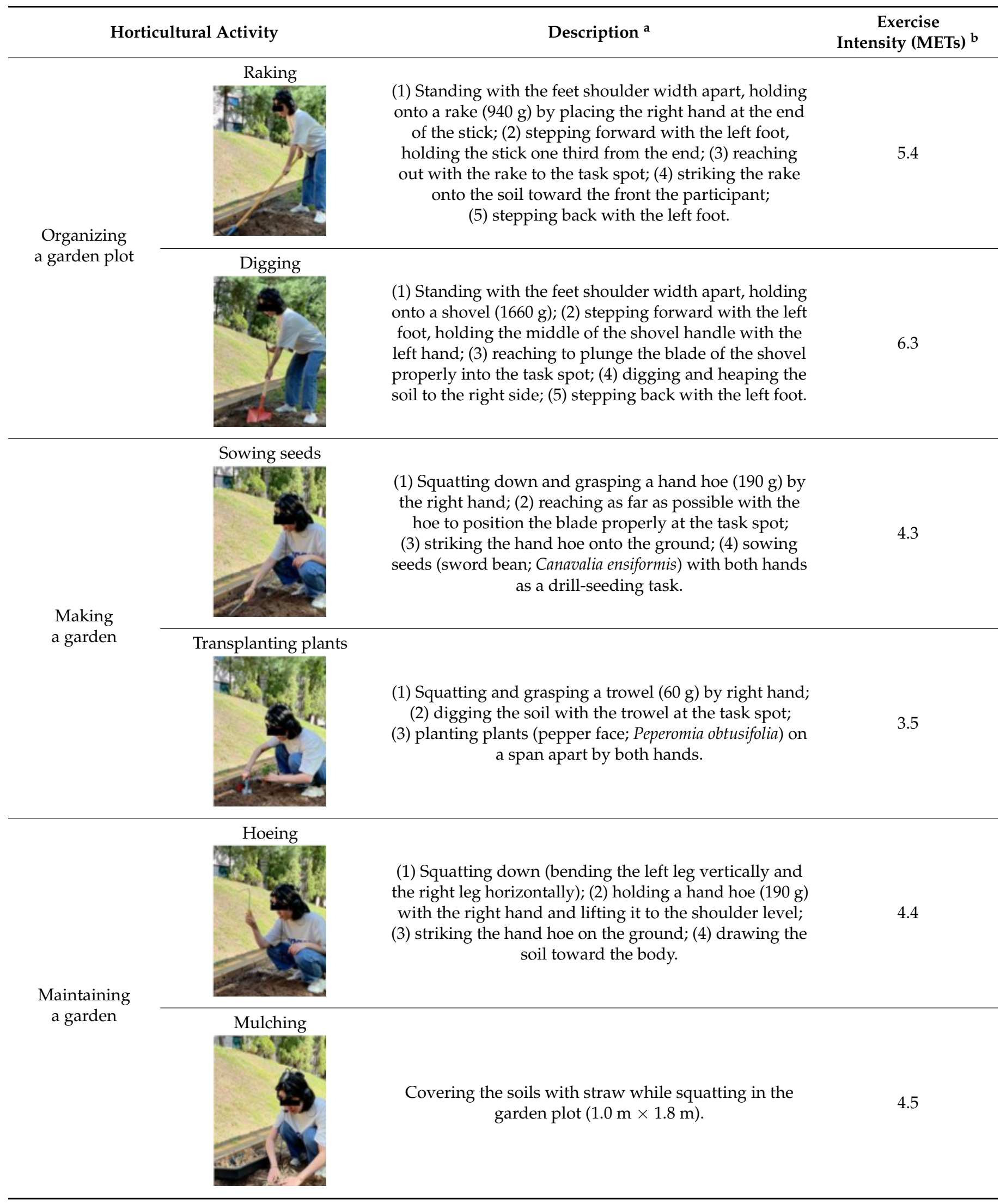


Table 2. Cont.

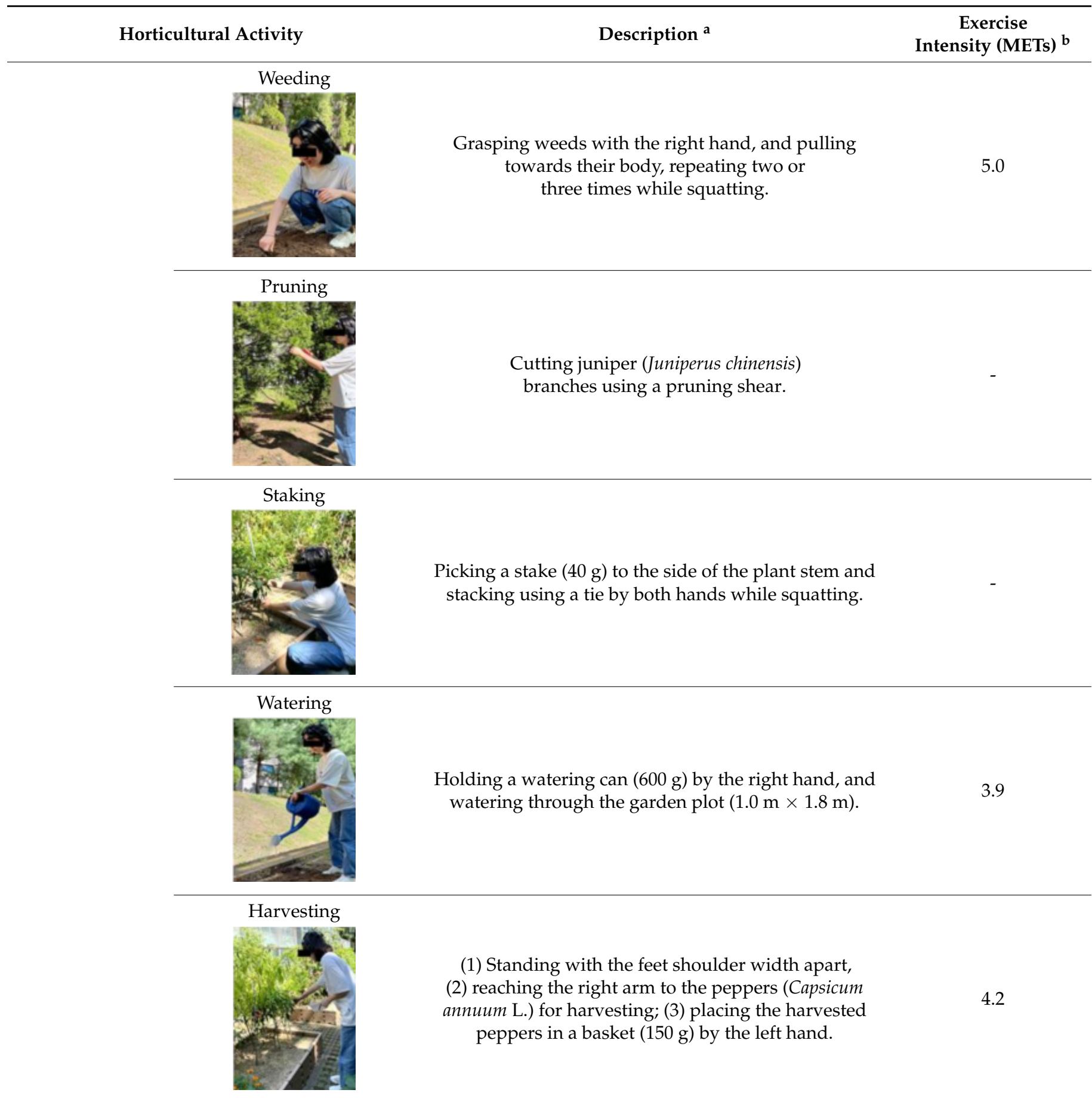

${ }^{a}$ The listed descriptions of a standard operating procedure are adapted from Lee et al., (2018) and Park et al., (2014) [23,34]. ${ }^{\mathrm{b}}$ The exercise intensities of horticultural activity for adults in 20s are referenced by Park et al., (2014) [23]. Metabolic equivalent of task (MET) represents the exercise intensity of physical activity in terms of oxygen consumption per unit body mass $\left(1 \mathrm{MET}=3.5 \mathrm{~mL} \cdot \mathrm{O}_{2} / \mathrm{kg} / \mathrm{min}\right)$ [35]. Less than 3 METs indicate low intensity, 3-6 METs are moderate intensity, and above 6 METs are high intensity physical activity [36].

\subsection{Measurement}

\subsubsection{Electroencephalography (EEG)}

We used a wireless dry EEG device (Quick-20; Cognionics, San Diego, CA, USA) to measure the brain waves of the participants while conducting the HA tasks. The dry type of EEG device employs electrolyte gel, featuring a minimized risk of an electric shock compared with the wet type systems. Dry electrodes applied to the scalp of the EEG device 
can amplify and process measured electrical signals. These signals were collected for data analysis. The safety of using this device has been certified by the European Commission and the Federal Communications Commission [30,31]. The electrode arrangements for the data collection followed the international 10- to 20-electrode arrangement system [37] while setting the reference electrode attached to the left earlobe (A1). The prefrontal cortex (PFC) in the brain governs cognitive control functions by affecting attention, impulse inhibition, prospective memory, and cognitive flexibility [38]. The EEG results measured from the left (Fp1) and right (Fp2) PFC channels are known to be involved in cognitive function (Figure 2) [39].

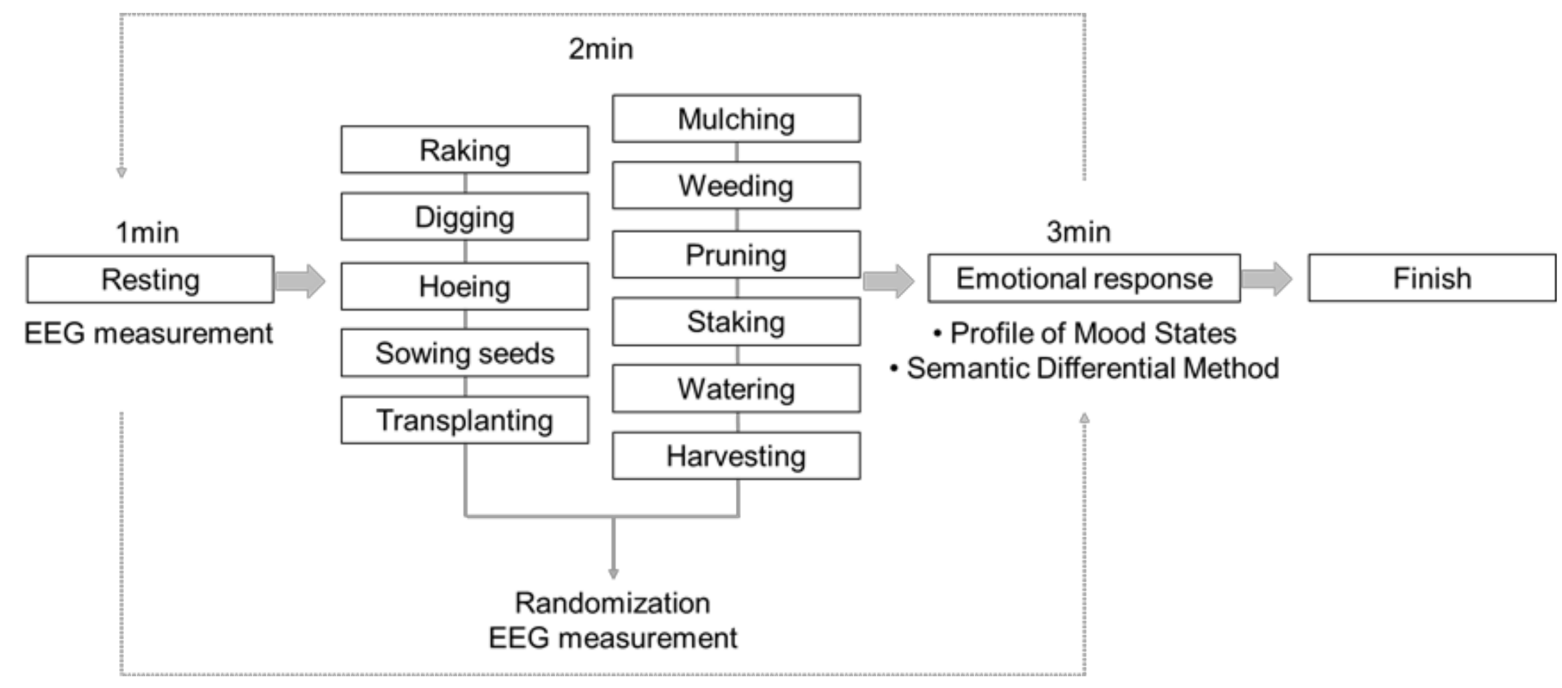

Figure 1. The experimental protocol used in this study.
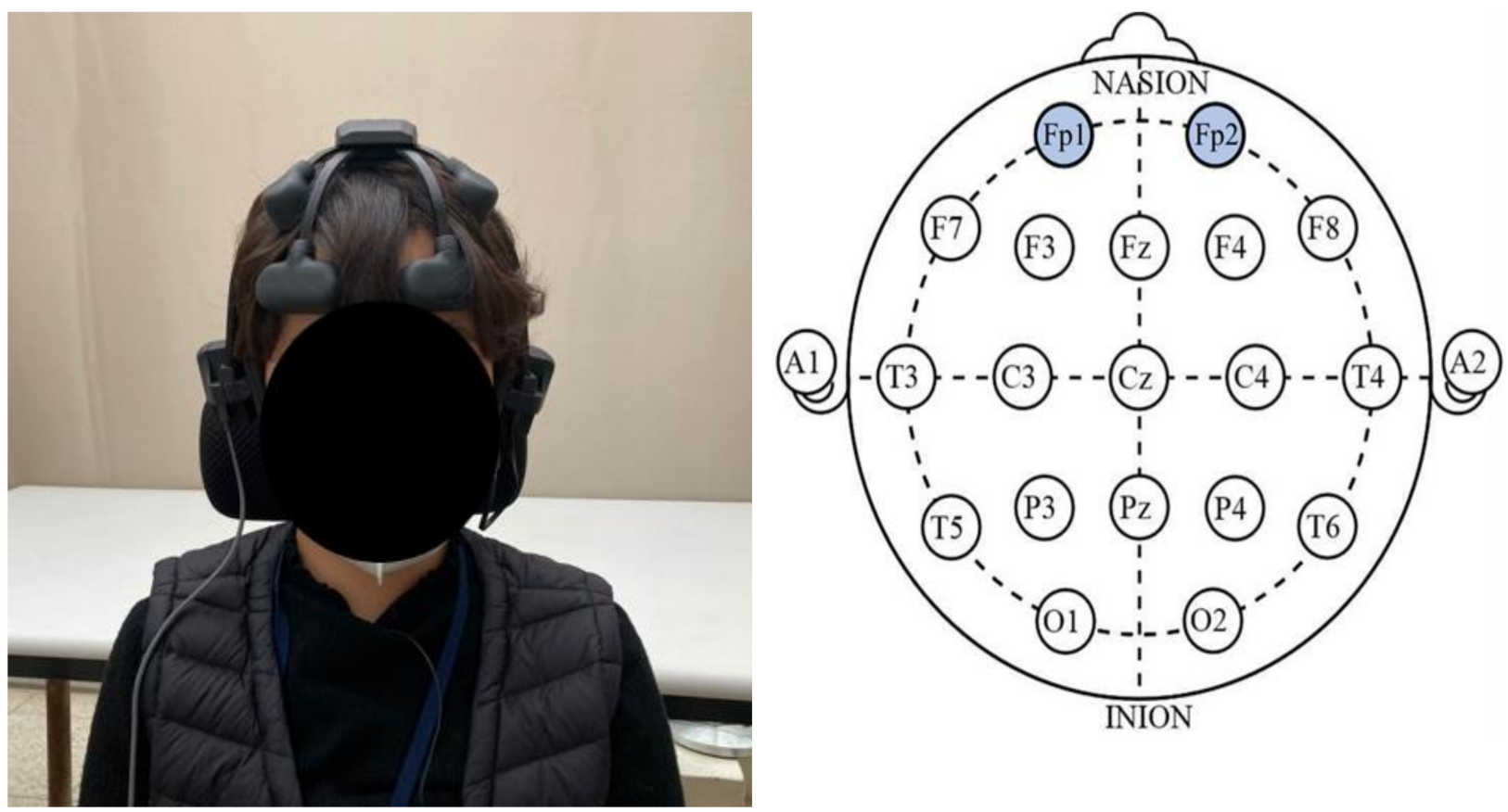

Figure 2. (Left) the wireless electroencephalography (EEG) device (Quick-20; Cognionics, San Diego, CA, USA) worn by a participant in the study. (Right) The electrode locations of the international 10-20 system for EEG recording [37]. 


\subsubsection{Profile of Mood States (POMS) and Semantic Differential Method (SDM)}

After conducting each HA task for $2 \mathrm{~min}$, we evaluated the emotional responses of the participants to HA tasks using the POMS and SDM questionnaire-based metrics. The POMS was developed by Shin [40], referring to the original literature, McNair et al. [41]. This metric contains 30 questions, which are classified into six emotional states of the participants as follows: "Tension and Anxiety (T-A)", "Depression (D)", "Anger and Hostility (A-H)", "Vigor (V)", "Fatigue (F)", and "Confusion (C)". A 5-point scale is used in each question to evaluate the emotional reactions from 1 (Not at all) to 5 (Very much). The responses were further evaluated by estimating the total mood disturbance (TMD) score using the following formula: TMD score $=(\mathrm{T}-\mathrm{A})+(\mathrm{D})+(\mathrm{A}-\mathrm{H})+(\mathrm{F})+(\mathrm{C})-(\mathrm{V})$. Lower scores present more positive moods of the participants [42].

The SDM was developed by Osgood et al. [43] and is commonly used to measure the emotional states of the participants like the POMS. This metric contains 3 questions with the three classified descriptor scales: "comfortable-uncomfortable," "natural-artificial," and "relaxed-awakening." The responses are measured on a 13-point Likert scale, where higher scores present more positive emotions of the participants, rather than the POMS. The Cronbach's $\alpha$ was $=0.7$ [41].

\subsubsection{Data Processing and Analysis}

We analyzed the collected EEG data using the Cognionics Data Acquisition (Cognionics) and Telescan 2.2 (Cognionics) software packages. First, as per the frequency band (4-50 Hz), brain waves from PFC were separated into four signature waves-theta $(4-8 \mathrm{~Hz})$, alpha $(8-13 \mathrm{~Hz})$, beta $(13-30 \mathrm{~Hz})$, and gamma waves $(30-50 \mathrm{~Hz})$ [44]. Then, we processed the first-hand brain waves and parameterized into four indicators-relative beta power spectrum (RB), sensory-motor rhythm (SMR)/theta spectrum, spectral edge frequency of 50 (SEF50), and spectral edge frequency as $50 \%$ of alpha (ASEF50). These parameters are interpreted as the overall attention levels of the participants based on the total frequency band [45]. These parameters are also used to represent different states of the brain in attention as described below (Table 3) [46-49].

Table 3. EEG power spectrum indicators used in this study.

\begin{tabular}{|c|c|c|c|}
\hline Analysis Indicator & $\begin{array}{l}\text { The Full Name of the EEG } \\
\text { Power Spectrum Indicator }\end{array}$ & Indicator Estimate (Ratio) & Attention State \\
\hline $\mathrm{RB}$ & Relative Beta & $\begin{array}{l}\text { Beta }(13-30 \mathrm{~Hz}) / \text { total } \\
\text { frequency }(4-50 \mathrm{~Hz})\end{array}$ & $\begin{array}{l}\text { Attentive status, being } \\
\text { engaged in problem-solving, } \\
\text { making decisions }\end{array}$ \\
\hline SMR/theta & Sensory Motor Rhythm to theta & Lower beta $(12-15 \mathrm{~Hz}) /$ theta $(4-8 \mathrm{~Hz})$ & Immersion state of individuals \\
\hline SEF50 & $\begin{array}{l}\text { Spectral Edge Frequency } 50 \% \text { of } \\
\text { Total Spectrum Band }\end{array}$ & $\begin{array}{l}\text { The lowest frequency below which } \\
50 \% \text { of the total power in the total } \\
\text { frequency band }(4-50 \mathrm{~Hz})\end{array}$ & Awareness \\
\hline ASEF50 & $\begin{array}{l}\text { Spectral Edge Frequency } 50 \% \text { of } \\
\text { Alpha Spectrum Band }\end{array}$ & $\begin{array}{l}\text { The lowest frequency below which } \\
50 \% \text { of the total power in the alpha } \\
\text { frequency }(8-13 \mathrm{~Hz})\end{array}$ & $\begin{array}{l}\text { Adequate awareness with } \\
\text { stability and relaxation }\end{array}$ \\
\hline
\end{tabular}

We performed a one-way ANOVA to examine each HA task on the EEG parameters and the POMS and SDM scores using SPSS (version 25 for Windows; IBM, Armonk, NY, USA). For post-hoc mean separation of those data, we conducted Duncan's multiple range test on SPSS. In these statistical analyses, $p<0.05$ was set to be significant in comparisons. We used Microsoft Excel (Office 2007; Microsoft Corp., Redmond, WA, USA) to compute descriptive statistics of the demographic data. 


\section{Results}

3.1. $E E G$

Overall, all of the EEG parameters analyzed-the RB, SMR/theta, SEF50, and ASEF50-increased when the participants were performing different HA tasks compared to the baseline measurement during the resting period (Table 4). Between the two regions of PFC areas, Fp1 and Fp2, no differences were observed, rather showing similar trends of the activation status of those four parameters. In addition, it was noted that different HA tasks made the participants show the featured activation patterns of the four parameters (Table 4). Among those HA tasks, the raking task increased the RB and ASEF50 of both PFC more than the other HA tasks. Similarly, when performing the digging task, the RB, SMR/theta, and ASEF50 also increased the most among the other tasks. During the pruning task, the SEF50 was higher than during the other tasks (Table 4).

Although overall activation patterns of HA tasks were similar, the RB, SMR/theta, and SEF50 were different by gender (Table 4). In the male participants, the RB and ASEF50 in both PFC were significantly higher during the raking task; the RB and ASEF50 in right $\mathrm{PFC}$ were significantly higher activation during the digging and mulching tasks, and the SMR/theta and SEF50 in both PFC were significantly higher during the digging and pruning task, respectively, than those during the other tasks (Table 4). In the female participants, the RB, SMR/theta in both PFC, and the ASEF50 in the right PFC were significantly higher during the digging task; and the SEF50 and ASEF50 in both PFC were significantly higher during the pruning and raking, respectively than those during the other tasks (Table 4).

\subsection{Profile of Mood States (POMS) and Semantic Differential Method (SDM)}

The subjective evaluation of the emotional states, while the participants' performing HA tasks, was conducted using the POMS questionnaire. The results of the POMS demonstrated that the TMD scores were significantly different between HA tasks and resting (Table 5). The TMD score during resting was greater than those during HA, indicating that the emotional state was positively changed when the participants conducted the HA tasks. Regarding the detailed six emotional states, differences were observed in vigor, tension and anxiety, and fatigue indices, whereas no differences were observed in depression, anger and hostility, and confusion indices. The participants experienced the most vigor and fatigue during the digging and the raking for the organization of a garden plot tasks. Furthermore, compared with the other tasks, when participating in the digging task, they experienced the highest tension and anxiety. Regarding gender, the male participants experienced the most tension and anxiety when digging. The female participants experienced the most vigor and fatigue when digging and raking for the organizing of garden plot tasks.

The results of the SDM survey showed that each score (e.g., being comfortable, being natural, and being relaxed) that participants felt were significantly different among HA tasks (Figure 3). When harvesting, participants experienced the most comfortable feeling compared to when participating in the other HA tasks. Furthermore, when harvesting and transplanting, they experienced the highest natural and relaxed feelings over the other HA tasks. Regarding gender, there were no significant differences in the SDM scores of the different takes in the male participants. The female participants felt the most comfortable and relaxed when harvesting and felt the most natural when transplanting. 


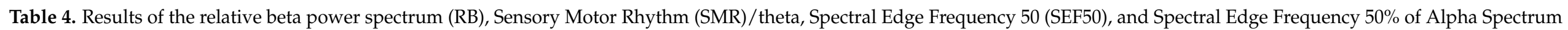
Band (ASEF50) by electroencephalography according to the horticultural activities.

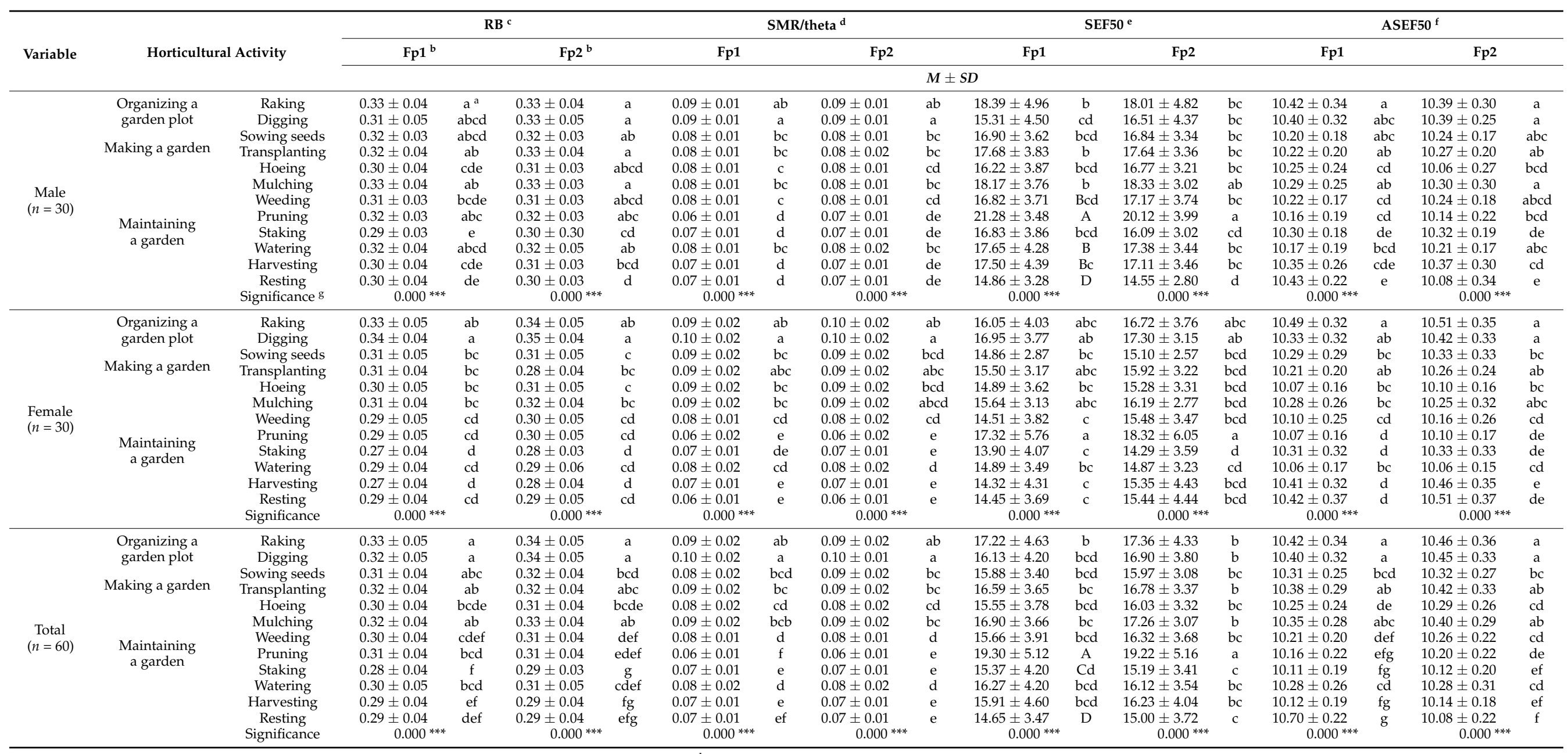

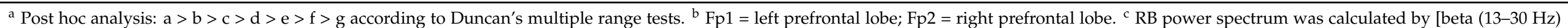

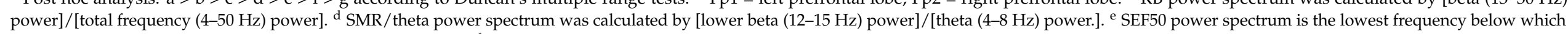

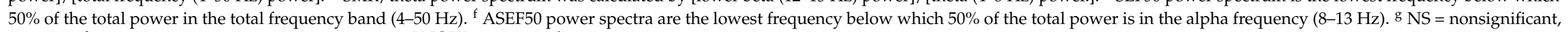
$* * *=$ significant at $p<0.05,0.01,0.001$ using one-way ANOVA, respectively. 
Table 5. Result of emotion state change by Profile of mood states (POMS) ${ }^{a}$ according to the horticultural activities.

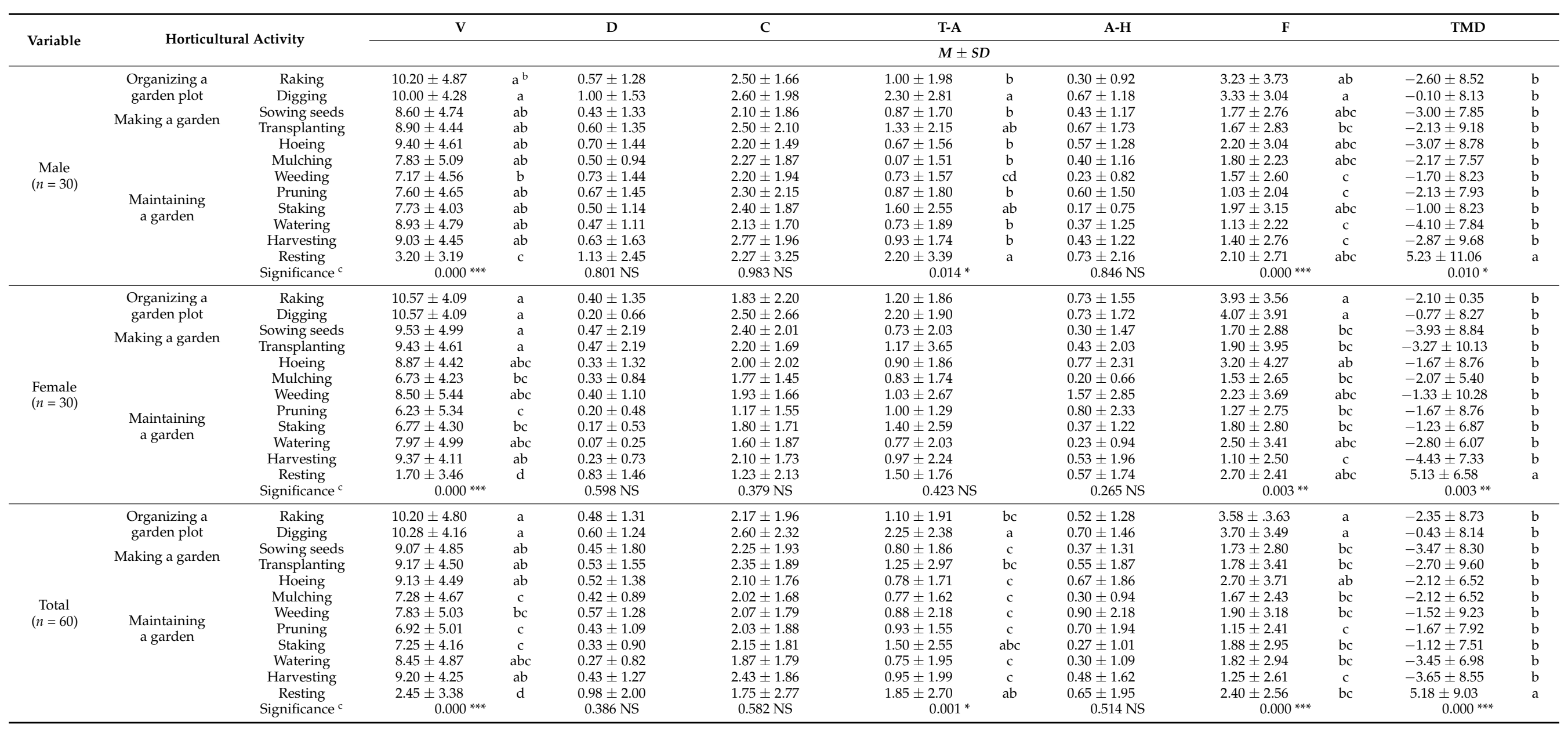

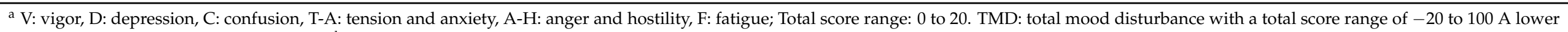

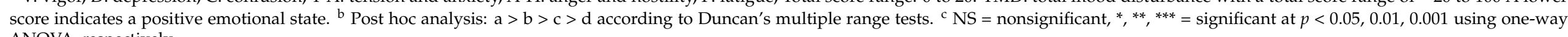
ANOVA, respectively. 
(A) Being comfortable

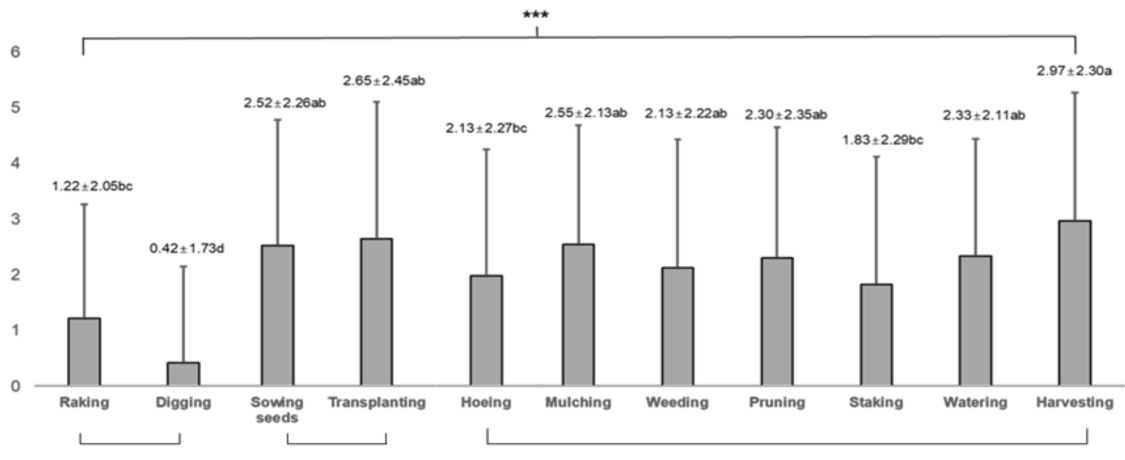

(B) Being natural

***

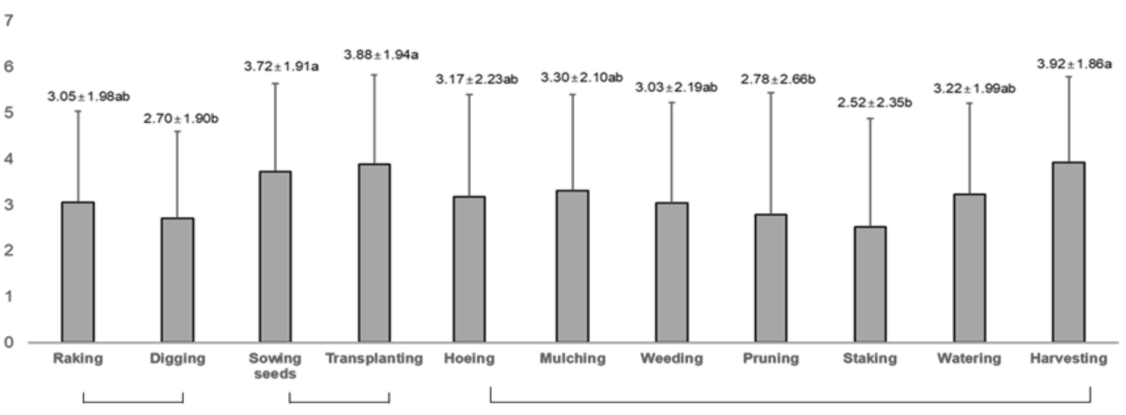

(C) Being relaxed

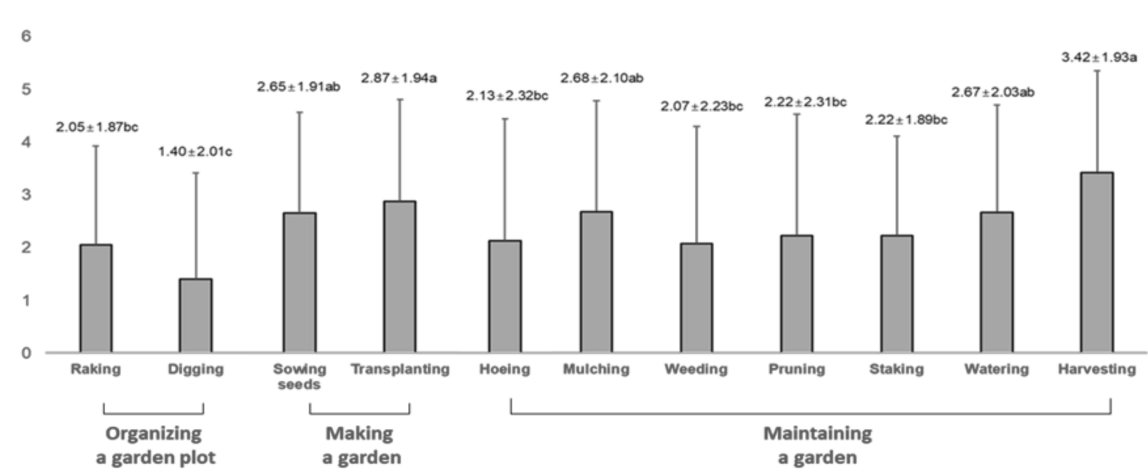

Figure 3. Comparison of a semantic differential method (SDM) for each horticultural activity task of 20s participants $(n=60)$. Data are presented as $M \pm$ SD; (A) Being comfortable, (B) Being natural, (C) Being relaxed. ${ }^{* *}$, Significant $p<0.001$ according to the one-way analysis of variance, post hoc analysis $\mathrm{a}>\mathrm{b}>\mathrm{c}>\mathrm{d}$ according to Duncan's multiple range tests. The score ranges from -6 to +6 . The higher the value is, the more positive the emotional state presents.

\section{Discussion}

In this pilot study, we characterized various HA based on brain function and emotional state of the participants and demonstrated that each HA task affected brain activation and emotional state in different ways. For EEG, each HA task showed a tendency to have higher brain activity of the EEG parameters (i.e., RB, SMR/theta, SEF50, and ASEF50) related to concentration when compared to the resting state. The RB and the ASEF50 of the participants performing the garden plot organization tasks, such as digging and raking, were especially activated higher than those during the other HA tasks. In addition, the pruning task increased the SEF50 the most for both male and female participants in comparison with the other HA tasks. These three HA tasks all require dexterous hand 
skills to use tools to perform tasks. Especially, when pruning, the participants selectively remove branches of plants using a cutting tool, taking care not to damage the plant as much as possible [50]. These fine motor skills and decision-making of branches to cut may necessitate a higher attention level, indicated by increased brain activity. When performing $\mathrm{HA}$, the increased brain wave activation is likely because most of the HA tasks used in the study were moderate-intensity physical activity for adults in their 20s [23]. The highest activation of brain waves during the garden plot organizing tasks is thought to be the result of having relatively high exercise intensity compared to the other HA tasks [23]. From a physiological point of view, increasing the amount of blood flow and oxygen in PFC during moderate-intensity physical activity leads to activation of PFC. For this activation mechanism, moderate-intensity physical activity enhances the cognitive function, one of the main functions of PFC, which, in turn, leads to increased attention and concentration [51,52]. In addition, previous studies reported that moderate-intensity physical activity increases the BDNF level, a neurotrophic factor related to memory, in the hippocampus in terms of cranial nerves [24,53,54]. Park et al. [53] reported that the BDNF levels in 41 elderly adults increased as a result of a 20-min low-to-moderate HA intervention.

The results of this pilot study showed that there were differences, by gender, in the EEG responses of the participants' performing HA tasks. In previous studies, when performing cognitive tasks such as intensive assignments and divergent thinking, changes in EEG were also reported differently by gender [55]. This can be explained by many intrinsic factors: The structural and functional differences of the brain by genders such as cerebral blood flow, psychoneuroendocrine response to stress and challenging situations, and morphological, neurochemical, and neurophysiological data of the sex dimorphism in hemispheric interactions [56-58].

According to the POMS results, responses to the participants' overall emotional states during HA task were positively altered compared with resting state. The participants reported that they felt negative emotions, such as fatigue and tension, but simultaneously feeling the most vigor during the garden plot organizing tasks. The highest levels of fatigue and tension during the digging and raking task were likely from the higher exercise intensity compared to the other HA tasks. Studies reported that through physical activity, various emotional states are changed, indicating positive and negative emotions both could be felt at the same time, and negative emotions such as fatigue and tension decrease from $10 \mathrm{~min}$ after the start of the activity $[59,60]$. Therefore, it is judged that negative/positive emotions coexisted because the participants performed each HA task for $2 \mathrm{~min}$ and investigated the emotion changes over the course of the measurements in the study. It is also reported that when individuals are exposed to nature, greater emotional relaxation and stress reduction were observed when performing more dynamic activities within a green environment $[61,62]$. Previous studies have also reported that HA leads to positive mood changes $[31,63,64]$. In another study, 27 elderly adults showed positive mood changes after participating in indoor horticultural activities, with a 40-min session for each activity, such as making a grass doll, making a topiary, dying the fabric using plants, and smelling and tasting herbs, especially smelling and tasting herbs and dying the fabric using plant showed the most positive mood (TDM score) changes. When emotional changes during horticulture and other recreational activities were investigated, HA tasks such as arranging flowers, transplanting, and washing leaves produced the highest positive mood changes [32]. The average TDM scores of the 11 horticultural activities in this study $(-0.43 \pm 8.14$ to $-3.65 \pm 8.55)$ also added evidence for this claim, compared to other recreational activities; for instance, walking with unfamiliar $\operatorname{dog}(-1.0 \pm 1.7)$, yoga and meditation in forest $(1.06 \pm 11.09)$, swimming $(9.00 \pm 20.00)$, playing video game (11.05 \pm 16.75$)$, and weightlifting (9.54 \pm 24.27$)$ [65-68].

For the SDM results, there was a significant difference between HA tasks, and in particular, the participants responded that they felt the most positive emotions, such as natural, relaxed, and comfortable feel while harvesting and transplanting plants. These results are considered to be due to psychophysiological relaxation and stabilization effects 
because they have the characteristics of plant-based horticultural tasks that directly touch and use green living plants in the process of harvesting and transplanting plants compared to the other HA tasks tested in the study [25,69]. Visual stimulation by green plants and plant-based activity results in physiological stability and relaxation, including increases in alpha waves, stabilization of the autonomic nervous system, and a decrease in oxy- $\mathrm{Hb}$ level $[25,69]$. Previous studies reported adults in their 20s felt calmer and more comfortable, relaxed, and natural when engaged in plant-based activities [25,70]. Similarly, it was found that children felt more natural and relaxed when performing HA tasks like harvesting, transplanting, and mixing soil rather than other leisure and physical activities [30]. For example, children felt more natural than in their common leisure and physical activities such as ball-playing, watching a video, folding paper $(0.77 \pm 2.43$ to $2.13 \pm 2.69)$ when performing horticultural activities $(3.97 \pm 2.20$ to $4.20 \pm 2.06)$ by SDM scores. It was also shown in the same study that children had higher levels of brain activation-related parameters while harvesting than other tasks. Our results, thus, are in line with such findings of the effects of plant-based activities on EEG and subjective mood conditions. This study was derived from a controlled pilot study designed to investigate the unique psychophysiological characteristics of each HA for $2 \mathrm{~min}$. There is a difference from the actual HA performance environment. Therefore, the results of this study have limitations in not sufficiently explaining the continuous health benefits that can be obtained through HA. For this reason, we suggest that long-term and longitudinal studies using EEG and wearable devices are necessary for the psychophysiological effects that last during and after an actual longer duration of HA. In addition, based on the feasibility confirmed in this pilot study, the main study on the effectiveness of HA intervention on cognitive and emotional aspects is needed by using evaluation tools that can clinically evaluate cognitive function and mental health.

\section{Conclusions}

The results of this pilot study showed that the $11 \mathrm{HA}$ tasks, serving as physical activities, increased brain activity in the prefrontal cortex and positively changed subjective emotional condition during a short time of tasking spans. In particular, digging, raking, and pruning were the most effective in the brain activation of the participants. The 'system leverage point' mechanism, in which specific interventions connecting people and nature can bring about systemic change that promotes sustainability, defines material, experience, cognition, and emotion as key connecting elements [19]. Horticultural activity is judged to be suitable as an intervention to connect nature and humans for sustainability in that it brings about positive cognitive and emotional changes through direct physical activity using a plant material [19]. The scientific and objective indicators derived from this study will serve as reference data for developing a horticultural activity intervention as green exercise to allow an active connection with nature. In future studies, it is necessary to investigate the psychophysiological characteristics of each horticultural activity task for different age groups and various client groups. It will also require longitudinal approaches to elucidate the effects of HA programs in practice (i.e., over the whole duration of the activities) on attention and emotional stability using EEG and wearable devices. In addition, in order to generalize the feasibility observed in this pilot study, it is necessary to identify cognitive and emotional benefits of HA using evaluation tools that can measure cognitive function and mental health in actual clinical practice.

Author Contributions: The following statements of authors contributions: Conceptualization, S.-O.K. and S.-A.P.; methodology, S.-O.K. and S.-A.P.; Formal analysis, S.-O.K.; writing-original draft preparation, A.-Y.L.; writing-review and editing, A.-Y.L.; supervision, S.-A.P.; funding acquisition, S.-A.P. All authors have read and agreed to the published version of the manuscript.

Funding: This research received no external funding. 
Institutional Review Board Statement: The study was conducted according to the guidelines of the Declaration of Helsinki, and approved by the Institutional Review Board of Konkuk University (7001355-201809-HR-268, 23 October 2018).

Informed Consent Statement: Informed consent was obtained from all subjects involved in the study.

Data Availability Statement: The datasets generated for this study are available on request to the corresponding author.

Acknowledgments: This paper was supported by the KU Research Professor Program of Konkuk University.

Conflicts of Interest: The authors declare no conflict of interest. The funders had no role in the design of the study; in the collection, analyses, or interpretation of data; in the writing of the manuscript, or in the decision to publish the results.

\section{References}

1. Lee, M.S.; Lee, J.; Park, B.J.; Miyazaki, Y. Interaction with Indoor Plants May Reduce Psychological and Physiological Stress by Suppressing Autonomic Nervous System Activity in Young Adults: A Randomized Crossover Study. J. Physiol. Anthropol. 2015, 34, 21. [CrossRef] [PubMed]

2. Dėdelè, A.; Miškinytè, A.; Andrušaitytè, S.; Bartkutè, Z. Perceived Stress among Different Occupational Groups and the Interaction with Sedentary Behaviour. Int. J. Environ. Res. Public Health 2019, 16, 4595. [CrossRef]

3. Magnon, V.; Vallet, G.T.; Dutheil, F.; Auxiette, C. Sedentary Lifestyle Matters as Past Sedentariness, not Current Sedentariness, Predicts Cognitive Inhibition Performance among College Students: An Exploratory Study. Int. J. Environ. Res. Public Health 2021, 18, 7649. [CrossRef] [PubMed]

4. Hall, G.; Laddu, D.R.; Phillips, S.A.; Lavie, C.J.; Arena, R. A tale of two pandemics: How Will COVID-19 and Global Trends in Physical Inactivity and Sedentary Behavior Affect One Another? Prog. Cardiovasc. Dis. 2021, 64, 108. [CrossRef] [PubMed]

5. Magnon, V.; Dutheil, F.; Auxiette, C. Sedentariness: A Need for a Definition. Front. Public Health 2018, 6, 372. [CrossRef]

6. Matthews, C.E.; Chen, K.Y.; Freedson, P.S.; Buchowski, M.S.; Beech, B.M.; Pate, R.R.; Troiano, R.P. Amount of Time Spent in Sedentary Behaviors in the United States, 2003-2004. Am. J. Epidemiol. 2008, 167, 875-881. [CrossRef]

7. Shephard, R.J. Physical Activity of Canadian Adults: Accelerometer Results from the 2007 to 2009 Canadian Health Measures Survey. Yearbook Sports Med. 2011, 22, 111-113. [CrossRef]

8. Lee, E.; Kim, Y. Effect of University Students' Sedentary Behavior on Stress, Anxiety, and Depression. Perspect. Psychiatric Care 2019, 55, 164. [CrossRef]

9. World Health Organizaion. Physical Activity. Available online: https://www.who.int/news-room/fact-sheets/detail/physicalactivity (accessed on 26 November 2020).

10. Choudhary, A.K.; Loganathan, S.; Maheshkumar, K. A Sedentary Lifestyle and Cognitive Function. Chall. Dis. Health Res. 2021, 6, 52-62. [CrossRef]

11. Fayyad, J.; Sampson, N.A.; Hwang, I.; Adamowski, T.; Aguilar-Gaxiola, S.; Al-Hamzawi, A.; Andrade, L.H.S.G.; Borges, G.; Girolamo, G.D.; Florescu, S.; et al. The Descriptive Epidemiology of DSM-IV Adult ADHD in the World Health Organization World Mental Health Surveys. Atten. Defic. Hyperact. Disord. 2017, 9, 47-65. [CrossRef]

12. Hung, S.H.; Chang, C.Y. Health Benefits of Evidence-based Biophilic-designed Environments: A Review. J. People Plants Environ. 2021, 24, 1-16. [CrossRef]

13. Barton, J.; Hine, R.; Pretty, J. The Health Benefits of Walking in Greenspaces of High Natural and Heritage Value. J. Integr. Environ. Sci. 2009, 6, 261-278. [CrossRef]

14. Wilson, E.O. Biophilia; Harvard University Press: Cambridge, UK, 1984.

15. Kaplan, S.; Kaplan, R. The Experience of Nature. A Psychological Perspective; Cambridge University Press: Cambridge, UK, 1989 ; p. 340.

16. Ulrich, R.S. Natural versus Urban Scenes: Some Psychophysiological Effects. Environ. Behav. 1981, 13, 523-556. [CrossRef]

17. Bratman, G.N.; Hamilton, J.P.; Daily, G.C. The Impacts of Nature Experience on Human Cognitive Function and Mental Health. Ann. N. Y. Acad. Sci. 2012, 1249, 118-136. [CrossRef]

18. Park, S.A.; Lee, A.Y.; Park, H.G.; Son, K.C.; Kim, D.S.; Lee, W.R. Gardening Intervention as a Low-to moderate-intensity Physical Activity for Improving Blood Lipid Profiles, Blood Pressure, Inflammation, and Oxidative Stress in Women over the Age of 70: A Pilot Study. HortScience 2017, 52, 200-205. [CrossRef]

19. Ives, C.D.; Abson, D.J.; Wehrden, H.V.; Dorninger, C.; Klaniecki, K.; Fischer, J. Reconnecting with Nature for Sustainability. Sustain. Sci. 2018, 13, 1389-1397. [CrossRef]

20. Wu, J. Urban Sustainability: An Inevitable Goal of Landscape Research. Landsc. Ecol. 2010, 25, 1-4. [CrossRef]

21. Pretty, J. How Nature Contributes to Mental and Physical Health. Spiritual. Health Int. 2004, 5, 68-78. [CrossRef]

22. Park, S.A.; Lee, A.Y.; Kim, J.J.; Lee, K.S.; So, J.M.; Son, K.C. Electromyographic Analysis of Upper and Lower Limbs Muscles during Gardening Tasks. Korean J. Hort. Sci. Technol. 2014, 32, 710-720. [CrossRef]

23. Park, S.A.; Lee, A.Y.; Lee, K.S.; Son, K.C. Gardening Tasks Performed by Adults are Moderate- to High-Intensity Physical Activities. HortTechnology 2014, 24, 1-6. [CrossRef] 
24. Park, S.A.; Son, S.Y.; Lee, A.Y.; Park, H.G.; Lee, W.L.; Lee, C.H. Metabolite Profiling Revealed that a Gardening Activity Program Improves Cognitive Ability Correlated with BDNF Levels and Serotonin Metabolism in the Elderly. Int. J. Environ. Res. Public Health 2020, 17, 541. [CrossRef]

25. Park, S.A.; Song, C.; Choi, J.Y.; Son, K.C.; Miyazak, Y. Foliage Plants Cause Physiological and Psychological Relaxation as Evidenced by Measurements of Prefrontal Cortex Activity and Profile of Mood States. HortScience 2016, 51, 1308-1312. [CrossRef]

26. Lee, M.J.; Kim, J.; Oh, W.; Jang, J.S. Effects of Indoor Horticultural Activities on Improvement of Attention and Concentration in Elementary School Students. Korean J. Hort. Sci. Technol. 2013, 31, 821-827. [CrossRef]

27. Kotozaki, Y. Horticultural Activity Improves Postpartum Women's Cognitive Function: Preliminary Evidence from an Exploratory Pilot Study. Cogent Psychol. 2020, 7, 1851003. [CrossRef]

28. Niedermeyer, E.; da Silva, F.L. Electroencephalography: Basic Principles, Clinical Applications, and Related Fields; EEG Recording and Operation of the Apparatus; Lippincott Williams and Wilkins: Baltimore, MD, USA, 2004.

29. Kim, D.W.; Kim, M.S.; Kim, S.P.; Park, Y.M.; Park, J.Y.; Bae, K.Y.; Lee, S.H.; Lee, J.W.; Lim, C.H.; Jeon, Y.H.; et al. Understanding and Application of EEG; Hakjisa: Seoul, Korea, 2017.

30. Kim, S.O.; Jeong, J.E.; Oh, Y.A.; Kim, H.R.; Park, S.A. Comparing Concentration Levels and Emotional States of Children Using Electroencephalography During Horticultural and Nonhorticultural Activities. HortScience 2021, 56, 324-329. [CrossRef]

31. Kim, S.O.; Pyun, S.B.; Park, S.A. Improved Cognitive Function and Emotional Condition Measured Using Electroencephalography in the Elderly During Horticultural Activities. HortScience 2021, 1, 1-10. [CrossRef]

32. Tarkka, I.M.; Hallett, M. Cortical Topography of Premotor and Motor Potentials Preceding Self-paced, Voluntary Movement of Dominant and Non-dominant Hands Electroencephalogr. Clin. Neurophysiol. 1990, 75, 36-43. [CrossRef]

33. Heckman, M.A.; Weil, J.; de Mejia, E.G. Caffeine (1,3, 7-trimethylxanthine) in Foods: A Comprehensive Review on Consumption, Functionality, Safety, and Regulatory Matters. J. Food Sci. 2010, 75, R77-R87. [CrossRef] [PubMed]

34. Lee, A.Y.; Park, S.A.; Moon, Y.J.; Son, K.C. Kinematic and Kinetic Analysis of Horticultural Activities for Postural Control and Balance Training. HortScience 2018, 53, 1541-1552. [CrossRef]

35. Ainsworth, B.E.; Haskell, W.L.; Whitt, M.C.; Irwin, M.L.; Swartz, A.M.; Strath, S.J.; O’Brien, W.L.; Bassett, D.R.; Schmitz, K.H.; Emplaincourt, P.O.; et al. Compendium of Physical Activities: An Update of Activity Codes and MET Intensities. Med. Sci. Sports Exerc. 2000, 32, 498-516. [CrossRef]

36. Pate, R.R.; Pratt, M.; Blair, S.N.; Haskell, W.L.; Macera, C.A.; Bouchard, C.; Buchner, D.; Ettinger, W.; Heath, G.W.; King, A.C.; et al. A Recommendation from the Centers for Disease Control and Prevention and the American College of Sports Medicine. J. Am. Med. Assn. 1995, 273, 402-407. [CrossRef]

37. Jasper, H.H. The ten-twenty electrode system of the international federation. Electroencephalogr. Clin. Neurophysiol. 1958, 10, 370-375.

38. Michel, M.; Morales, J. Minority Reports: Consciousness and the Prefrontal Cortex. Mind Lang. 2020, 35, 493-513. [CrossRef]

39. Miller, E.K.; Cohen, J.D. An Integrative Theory of Prefrontal Cortex Function. Annu. Rev. Neurosci. 2001, 24, 167-202. [CrossRef] [PubMed]

40. Shin, Y.H. A Study on Verification of the Profile of Mood States (POMS) for Korean Elders. J. Korean Acad. Nurs. 1996, 26, 743-758. [CrossRef]

41. McNair, D.M.; Lorr, M.; Droppleman, L.F. Manual for the Profile of Mood States; Educational Industrial Testing Service: San Diego, CA, USA, 1992.

42. Baker, F.; Denniston, M.; Zabora, J.; Polland, A.; Dudley, W.N. A POMS Short Form for Cancer Patients: Psychometric and Structural Evaluation. Psycho-Oncol. 2002, 11, 273-281. [CrossRef]

43. Osgood, C.E.; Suci, S.J.; Tannnenbaum, P.H. The Measurement of Meaning; Illinois University Press: Champaign, IL, USA, 1956.

44. Sowndhararajan, K.; Cho, H.; Yu, B.; Kim, S. Effect of Olfactory Stimulation of Isomeric Aroma Compounds, (+)-Limonene and Terpinolene on Human Electroencephalographic Activity. Eur. J. Integr. Med. 2015, 7, 561-566. [CrossRef]

45. Bakhtadze, S.; Beridze, M.; Geladze, N.; Khachapuridze, N.; Bornstein, N. Effect of EEG Biofeedback on Cognitive Flexibility in Children with Attention Deficit Hyperactivity Disorder With and Without Epilepsy. Appl. Psychophysiol. Biofeedback 2016, 41, 71-79. [CrossRef]

46. Gruzelier, J.; Egner, T.; Vernon, D. Validating the Efficacy of Neurofeedback for Optimising Performance. Prog. Brain Res. 2006, 159, 421-431. [CrossRef]

47. Kang, S.Y.; Kim, M.K.; Ryu, H.W. Influence of the Concentration of Lavender Oil on Brain Activity. Kor. J. Aesthet. Cosmetol. 2013, 11, 1099-1107.

48. Kora, P.; Meenakshi, K.; Swaraja, K.; Rajani, A.; Raju, M.S. EEG based Interpretation of Human Brain activity during Yoga and Meditation using Machine Learning: A systematic review. Complement. Ther. Clin. Pract. 2021, 43, 101329. [CrossRef] [PubMed]

49. Ryu, H.; Ko, W.; Kim, J.; Kim, S.; Kim, M. Electroencephalography Activities Influenced by Classroom Smells of Male High School. Sci. Emot. Sensib. 2013, 16, 387-396.

50. Lee, R. The Pruning Book, 2nd ed.; The Tauntion Press: Newtown, CT, USA, 2010.

51. Bhambhani, Y.; Malik, R.; Mookerjee, S. Cerebral Oxygenation Declines at Exercise Intensities Above the Respiratory Compensation Threshold. Respir. Physiol. Neurobiol. 2007, 156, 196-202. [CrossRef] [PubMed] 
52. Mekari, S.; Fraser, S.; Bosquet, L.; Bonnéry, C.; Labelle, V.; Pouliot, P.; Lesage, F.; Bherer, L. The Relationship between Exercise Intensity, Cerebral Oxygenation and Cognitive Performance in Young Adults. Eur. J. Appl. Physiol. 2015, 115, $2189-2197$. [CrossRef] [PubMed]

53. Park, S.A.; Lee, A.Y.; Park, H.G.; Lee, W.L. Benefits of Gardening Activities for Cognitive Function according to Measurement of Brain Nerve Growth Factor Levels. Int. J. Environ. Res. Public Health 2019, 16, 760. [CrossRef] [PubMed]

54. Piepmeier, A.T.; Etnier, J.L. Brain-derived Neurotrophic Factor (BDNF) as a Potential Mechanism of the Effects of Acute Exercise on Cognitive Performance. J. Sport Health Sci. 2015, 4, 14-23. [CrossRef]

55. Razumnikova, O.M. Gender Differences in Hemispheric Organization During Divergent Thinking: An EEG Investigation in Human Subjects. Neurosci. Lett. 2004, 362, 193-195. [CrossRef]

56. Gur, R.C.; Gur, R.E.; Obrist, W.D.; Hungerbuhler, J.P.; Younkin, D.; Rosen, A.D.; Skolnick, B.E.; Reivich, M. Sex and Handedness Differences in Cerebral Blood Flow During Rest and Cognitive Activity. Science 1982, 217, 659-661. [CrossRef]

57. Frankenhaeuser, M.; von Wright, M.R.; Collins, A.; von Wright, J.; Sedvall, G.; Swahn, C.G. Sex Differences in Psychoneuroendocrine Reactions to Examination Stress. Psychosom. Med. 1978, 40, 334-343. [CrossRef]

58. Volf, N.V.; Razumnikova, O.M. Sex Differences in EEG Coherence During a Verbal Memory Task in Normal Adults. Intl. J. Psychophysiol. 1999, 34, 113-122. [CrossRef]

59. Hansen, C.J.; Stevens, L.C.; Coast, J.R. Exercise duration and mood state: How much is enough to feel better? Health Psychol. 2001, 20, 267-275. [CrossRef] [PubMed]

60. Lane, A.M.; Crone-Grant, D.; Lane, H. Mood Changes Following Exercise. Percept. Mot. Skills 2002, 94, 732-734. [CrossRef] [PubMed]

61. Hartig, T.; Evans, G.W.; Jamner, L.D.; Davis, D.S.; Gärling, T. Tracking Restoration in Natural and Urban Field Settings. J. Environ. Psychol. 2003, 23, 109-123. [CrossRef]

62. Lin, W.; Chen, Q.; Jiang, M.; Tao, J.; Liu, Z.; Zhang, X.; Wu, L.; Xu, S.; Zeng, Q. Sitting or walking? Analyzing the Neural Emotional Indicators of Urban Green Space Behavior with Mobile EEG. J. Urban Health 2020, 97, 191-203. [CrossRef] [PubMed]

63. Hayashi, N.; Wada, T.; Hirai, H.; Miyake, T.; Matsuura, Y.; Shimizu, N.; Kurook, H.; Horiuchi, S. The Effects of Horticultural Activity in a Community Garden on Mood Changes. Environ. Control Biol. 2008, 46, 233-240. [CrossRef]

64. Tu, P.C.; Cheng, W.C.; Hou, P.C.; Chang, Y.S. Effects of Types of Horticultural Activity on the Physical and Mental State of Elderly Individuals. Int. J. Environ. Res. Public Health 2020, 17, 522. [CrossRef]

65. Adnan, M.W.; Sedek, R.; Mutalib, S.A.; Kasim, Z.M.; Kashim, M.I.A.M.; Idris, F.; Yusof, A. Effects of Swimming Towards Mental Health in Collegiate Male Adults. Malays. Appl. Biol. 2019, 48, 141-148.

66. Covington, A.C.; Rogers, R.R.; Kopec, T.J.; Ballmann, C.G. The Effect of Walking an Unfamiliar Versus Companion Dog on Mood, Exercise Enjoyment, and Heart Rate: A Pilot Field. Top. Exerc. Sci. Kinesiol. 2021, 2, 3.

67. Park, C.E.; Kim, D.J.; Park, K.S.; Shin, C.S.; Kim, Y.H. Effects of Yoga and Meditation-focused Forest Healing Programs on Profile of Mood States (POMS) and Stress Response of Adults. Korean J. Environ. Ecol. 2018, 32, 658-666. [CrossRef]

68. Wood, R.T.; Griffiths, M.D. Time Loss Whilst Playing Video Games: Is There a Relationship to Addictive Behaviours? Int. J. Ment. Health Addict. 2007, 5, 141-149. [CrossRef]

69. Tao, J.; Hassan, A.; Qibing, C.; Yinggao, L.; Li, G.; Jiang, M.; Li, D.; Nian, L.; Bing-Yang, L.; Ziqin, Z. Psychological and Physiological Relaxation Induced by Nature-working with Ornamental Plants. Discrete Dyn. Nat. Soc. 2020, 6784512. [CrossRef]

70. Hassan, A.; Qibing, C.; Tao, J.; Bing-Yang, L.; Nian, L.; Li, S.; Tng, L.Y.; Li, J.Z.; Ziyue, S.G.; Tahir, M.S. Effects of Plant Activity on Mental Stress in Young Adults. HortScience 2018, 53, 104-109. [CrossRef] 